\title{
Tumors of the Submandibular Gland: Our Management Experience at Sylvanus Olympio University Hospital in Lomé
}

\author{
Winga Foma ${ }^{1}$, , Bathokedeou Amana ${ }^{1}$, Haréfétéguéna Bissa ${ }^{1}$, Essobozou Pegbessou ${ }^{1}$, Saliou Adam $^{1}$, \\ Koffi Amegbor ${ }^{2}$, Essohanam Boko ${ }^{1}$, Eyawèlohn Kpemissi ${ }^{1}$ \\ ${ }^{1}$ Department of ENT/Head and Neck Surgery, Université de Lomé, Lomé, Togo \\ ${ }^{2}$ Department of Pathological Anatomy, Université de Lomé, Lomé, Togo
}

Email address:

adrienfoma@yahoo.fr (W. Foma)

${ }^{*}$ Corresponding author

\section{To cite this article:}

Winga Foma, Bathokedeou Amana, Haréfétéguéna Bissa, Essobozou Pegbessou, Saliou Adam, Koffi Amegbor, Essohanam Boko, Eyawèlohn Kpemissi. Tumors of the Submandibular Gland: Our Management Experience at Sylvanus Olympio University Hospital in Lomé. International Journal of Otorhinolaryngology. Vol. 5, No. 1, 2019, pp. 1-4. doi: 10.11648/j.ijo.20190501.11

Received: January 2, 2019; Accepted: January 24, 2019; Published: February 15, 2019

\begin{abstract}
The purpose of this survey was to describe the epidemiological, diagnostic and therapeutic aspects of submandibular gland tumors in our practice setting. This was a descriptive retrospective study of submandibular gland tumors treated in the ENT and cervico-maxillofacial surgery department of the Sylvanus Olympio University Hospital over a period of 15 years. Data were collected from patient records. During the study period, 25 tumor cases were collected and operated, representing $38.46 \%$ of the surgical pathology of the submandibular gland. The sex ratio $(\mathrm{m} / \mathrm{f})$ was 0.56 . The average age was 45.68 years old with extremes of 5 and 86 years old. The 45 to 60 age group was the most represented with 11 cases (44\%). Submandibulectomy was performed in all patients with supraomohyoid lymph node dissection in 4 cases based on clinical and ultrasound criteria for malignancy and intraoperative findings. The histology of the operative specimens found 6 malignant tumors (24\%) and 19 benign tumors (76\%). The pleomorphic adenoma was the most common histological type with 12 cases (48\%). The size of the tumor did not have a statistically significant impact on the benign or malignant nature of the tumor $(\mathrm{p}=$ $0.55)$. Similarly, the histological nature was not related to $\operatorname{sex}(\mathrm{p}=0.19)$. The immediate postoperative evolution was good in 22 cases and complicated in 3 cases. Two cases of carcinoma classified pT3 were referred for complementary radiotherapy. In conclusion, tumors of the submandibular gland are relatively rare and predominantly affect women in our context. The evolution under treatment is good but could still be improved by a good preoperative exploration including the fine-needle biopsy or even the MRI.
\end{abstract}

Keywords: Submandibular Gland, Salivary Gland Tumors, Pleomorphic Adenoma, Togo

\section{Introduction}

Tumors of the main salivary glands (parotid, submandibular, sublingual) and accessories, despite their morphological and histological diversity, are a rare entity among tumors of the head and neck. Dominated by parotid tumors, salivary gland tumors account for less than $1 \%$ of all body tumors and 3\% of head and neck tumors [1-3]. As for the pathology of the submandibular gland, it is essentially non-tumoral, dominated by sialadenites and sialolithiases; which tends to minimize the prevalence of tumors [4]. In the literature, about $10 \%$ of all salivary gland tumors are localized in the submandibular gland, with a high rate of malignant tumors $[2,5]$. The management of these tumors of the submandibular gland calls for imaging (ultrasound, CT and MRI) and surgery, which is most often diagnostic and therapeutic. The purpose of this study was to describe the epidemiological, diagnostic and therapeutic aspects of submandibular gland tumors in our practice setting. 


\section{Materials and Method}

This was a descriptive retrospective study of submandibular gland tumors treated in the ENT and cervicomaxillofacial surgery department of Sylvanus Olympio University Hospital from January 1st, 2003 to December 31 st, 2017, a period of 15 years. Data were collected from patient records. Biopsy was considered for inoperable tumors.

Included in this study were all patients treated for a tumor of the submandibular gland, with histological documentation. Patients whose ablation of the submandibular gland was made for sialolithiasis or inflammatory disease or lymph node dissection for carcinoma of the face or neck were not included in this study.

The parameters studied were the demographic data, the clinical and ultrasound characteristics of the tumor, the surgical treatment received, the post-operative evolution and the histological type.

The data were captured and analyzed using the Epi-Info 7 Software and the results were formatted using Excel 2013. The frequency comparison of the categorical variables was done using Pearson's Chi square test taking into account its conditions of validity and realization. Decisions were taken with a risk of $5 \%$.

\section{Results}

During the study period, 25 cases of tumors were collected and operated representing $38.46 \%$ of the surgical pathology of the submandibular gland, thus coming second after the lithiases. There were 16 women (64\%) and 9 men (36\%), a sex ratio $(\mathrm{M} / \mathrm{F})$ of 0.56 . The average age was 45.68 years old with extremes of 5 and 86 years old. The 45 to 60 age group was the most represented with 11 cases (44\%) (Figure 1 ). The duration of progression before consultation was on average 32.48 months with extremes of 6 months and 12 years. No case of inoperability was found. Ultrasound is the main paraclinical means of exploration of the submandibular gland in our practice becoming almost systematic. The size of the tumor evaluated on ultrasound averaged $54.04 \mathrm{~mm}$ on its longest axis with extremes of 17 and $130 \mathrm{~mm}$ and a predominance of the $50-70 \mathrm{~mm}$ segment (12 cases).

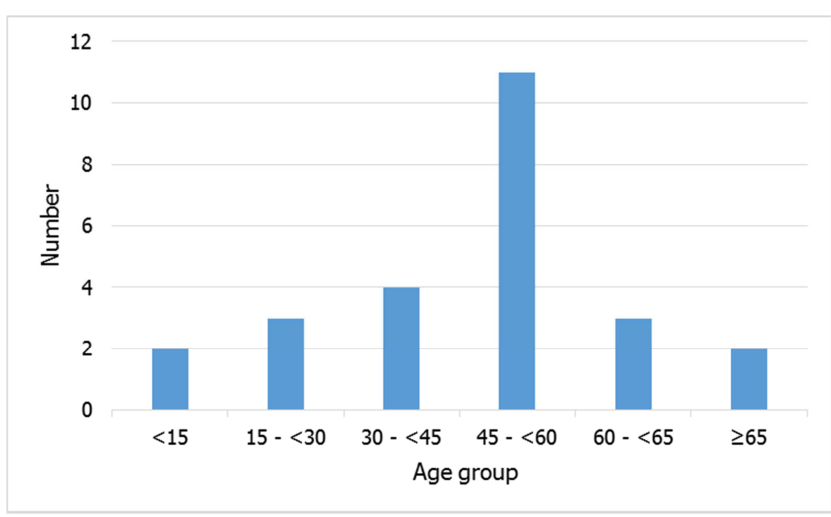

Figure 1. Distribution of patients by age group.

Submandibulectomy was performed in all patients with supraomohyoid lymph node dissection in 4 cases on the basis of clinical and ultrasonographic criteria of malignancy and intraoperative findings (painful tumor, poorly limited, hard consistency, very heterogeneous, attached to neighboring tissues, associated with adenomegaly of the mandibular lodge).

Histology of operative specimens found 6 malignant tumors $(24 \%)$ and 19 benign tumors (76\%) (Table 1). The pleomorphic adenoma was the most common histological type with 12 cases $(48 \%)$. Carcinomas were classified pT1 (mucoepidermoid carcinoma), pT2 (squamous cell carcinoma and mucoepidermoid carcinoma) and pT3 (squamous cell carcinoma and adenocarcinoma). The lymph node dissections were related to the 2 cases of squamous cell carcinoma, the case of adenocarcinoma and 1 case of pleomorphic adenoma of the submandibular gland (negative dissection). Histological examination of the lymph node tissue removed did not reveal any carcinomatous metastasis; adenomegalies being linked to reactive adenites.

Table 1. Distribution of the different histological entities.

\begin{tabular}{llll}
\hline Histological type & & Number & \% \\
\hline \multirow{3}{*}{ Malignant tumor } & adenocarcinoma & 1 & 4 \\
& Squamous cell carcinoma & 2 & 8 \\
& Mucoepidermoid carcinoma & 2 & 8 \\
& Diffuse large cell lymphoma & 1 & 4 \\
& Pleomorphic adenoma & 12 & 48 \\
Benign tumor & Monomorphic adenoma & 1 & 4 \\
& Tubular adenoma & 1 & 4 \\
& Fibroma & 3 & 12 \\
Total & Mucous cyst & 1 & 4 \\
& Serous cyst with glandular hyperplasia & 1 & 4 \\
\end{tabular}

The clinical and ultrasonographic characteristics of the tumors according to their histological natures are respectively detailed in Tables 2 and 3. The size of the tumor did not have a statistically significant impact on the benign or malignant nature of the tumor $(p=0.55)$. Similarly, the histological nature was not related to $\operatorname{sex}(p=0.19)$. 
Table 2. Clinical characteristics of tumors according to histological nature.

\begin{tabular}{|c|c|c|c|c|}
\hline & & Malignant tumor & Benign tumor & $\%$ \\
\hline \multirow{2}{*}{ Sensitivity } & Pain & 4 & 4 & 32 \\
\hline & Painless & 2 & 15 & 68 \\
\hline \multirow{3}{*}{ Consistency } & Renitent & 0 & 1 & 4 \\
\hline & Firm & 5 & 17 & 88 \\
\hline & Hard & 1 & 0 & 4 \\
\hline Mobility & Mobile & 5 & 18 & 92 \\
\hline \multirow{2}{*}{ Limits } & Well defined & 5 & 19 & 96 \\
\hline & Not well defined & 1 & 0 & 4 \\
\hline \multirow{3}{*}{ Other isolated signs } & Salivary colic & 0 & 1 & 4 \\
\hline & Multilobed & 0 & 3 & 12 \\
\hline & Adenopathy & 0 & 0 & 0 \\
\hline
\end{tabular}

Table 3. Ultrasound characteristics of tumors according to the histological nature.

\begin{tabular}{|c|c|c|c|}
\hline Ultrasound signs & & Malignant tumor & Benign tumor \\
\hline \multirow{2}{*}{ Aspect } & Homogeneous & 1 & 10 \\
\hline & Heterogeneous & 5 & 9 \\
\hline \multirow{3}{*}{ Contours } & Regulars & 6 & 15 \\
\hline & Irregular & 0 & 1 \\
\hline & Lobulated & 0 & 3 \\
\hline \multirow[b]{2}{*}{ Echogenicity } & Hypoechoic & 1 & 11 \\
\hline & Isoechoic & 2 & 4 \\
\hline \multirow{2}{*}{ Limits } & Sharp & 5 & 17 \\
\hline & Blurred & 1 & 2 \\
\hline \multirow{5}{*}{ Other isolated characteristics } & Calcifications & 0 & 1 \\
\hline & Calcifications and adenopathy & 1 & 0 \\
\hline & Zones of necrosis & 1 & 0 \\
\hline & Zones of necrosis and adenopathy & 1 & 0 \\
\hline & Posterior enhancement & 0 & 4 \\
\hline
\end{tabular}

The immediate postoperative evolution was good in 22 cases and complicated in 3 cases: 2 transient paralysis of the mental nerve branch of the facial nerve and 1 case of infection of the operating room which was disinfected by local treatment and antibiotherapy for about ten days. The duration of hospitalization was 5.32 days on average with extremes of 3 and 13 days. The 2 cases of pT3 were referred for complementary radiotherapy. Among the cases of malignancies, only the case of pT1 has not been overlooked after 4 years of decline and no adverse development was noted.

\section{Discussion}

The analysis of our series confirms some key aspects of submandibular gland tumors generally reported in the literature: rarity, female predominance, average age of discovery between 4th and 5th decade, histological diversity, predominance of pleomorphic adenoma, and surgical treatment essentially [3, 5-11]. Our series has been marked by a large clinical and ultrasound variability of tumors making it difficult to characterize the benign or malignant nature of tumors of the submandibular gland as evidenced by the case of negative dissection. In clinical terms, cervical tuberculosis, sarcoidosis and other granulomatoses, despite their rarity, are nosological entities comparable to tumors of the submandibular gland [8]. The anatomical interest of ultrasound tends to take precedence over the histological one in our practice. Although only the anatomopathological examination of the operative excision specimen can confirm the diagnosis of a tumor, more varied paraclinical investigations would help to better predict the histological nature of tumors of the submandibular gland and therefore the management. Ultrasound remains nevertheless a means of fundamental exploration of the masses of the submandibular lodge [4]. For some authors, ultrasonography and CT have a very limited role in the diagnosis of salivary gland tumor lesions; tumor characterization is better with MRI, which has become the gold standard examination for any suspicion of glandular mass [12]. For others, fine-needle aspiration can be a tool of real diagnostic interest in the assessment of salivary gland swelling, as well as imaging [13].

The size of the tumor did not have a statistically significant impact on the benign or malignant nature of the tumor in our series. Kucuk et al in Turkey in a series of salivary glands noted that the average size of benign tumors was only slightly less than that of malignant tumors $(2.90 \mathrm{~cm} / 3.77$ cm) [14].

Malignant tumors accounted for $24 \%$ in our series. Despite the overall trend of malignancy reported in the literature, the rate of malignant tumors of the submandibular gland remains highly variable: $42 \%$ in Germany [2], $17.39 \%$ and $20 \%$ in 2 Brazilian series [3, 15], 52.8\% in Nigeria [7], 60.87\% in Greece [8], 38.1\% in Senegal [11], 24\% in Turkey [14], 30\% 
in Uganda [16]. While adenoid cystic carcinoma is the histological type most commonly found in the submandibular gland $[1,5]$, mucoepidermoid and squamous cell carcinomas were the most common in our series. The prevalence of squamous cell carcinoma has been reported in Senegal and Togo respectively in the submandibular gland [11] and parotid gland [17]. The absence of skin lesions and lesions of the upper aerodigestive tract, which may suggest glandular metastases, suggest the possibility of epidermoid maturation of mucoepidermoid carcinomas. Although rare, mucoepidermoid carcinoma may experience epidermoid maturation within the salivary glands [10].

In addition to lymphomas, the treatment of tumors of the submandibular gland is almost always surgical, followed in some cases by radiotherapy [2, 7, 8, 12]. This surgery for diagnostic and therapeutic purposes, should respect, if possible, some structures of the submandibular region, such as the chin branch of the facial nerve, the lingual and hypoglossal nerves to avoid complications. Radiotherapy may be exclusive in the case of an inoperable tumor; postoperative in case of insufficient resection limits, highgrade malignancy tumor, extracapsular, perineural, bone, nodal or bulky tumor $[8,12]$.

\section{Conclusion}

Tumors of the submandibular gland are relatively rare and predominantly affect women in our context. The anatomical interest of ultrasound tends to take precedence over the histological one in our practice. Despite the overall trend of malignancy reported in the literature, the rate of malignant tumors of the submandibular gland remains highly variable. The evolution under treatment is good but could still be improved by a good preoperative exploration including the fine-needle aspiration or even the MRI.

\section{Conflicts of Interest}

Authors have declared that there is no conflict of interest.

\section{References}

[1] Uro-Coste E. Tumeurs des glandes salivaires: État des lieux en 2009. Ann Pathol 2009; 29 (4): 274-85.

[2] Preuss SF, Klussmann JP, Wittekindt C, Drebber U, Beutner D, Guntinas-Lichius O. Submandibular Gland Excision: 15 Years of Experience. J Oral Maxillofac Surg 2007; 65 (5): 953-7.

[3] Lima SS, Soares AF, de Amorim RF, Freitas Rde A.
Epidemiologic profile of salivary gland neoplasms: analysis of 245 cases. Rev Bras Otorrinolaringol 2005; 71 (3):3 35-40.

[4] Dalgic A, Karakoc O, Karahatay S, Hidir Y, Gamsizkan M, Birkent H, et al. Submandibular triangle masses. J Craniofac Surg 2013; 24 (5): 529-31.

[5] Btissam B, Saidi Z, Khaoula H, Youssef R, Lahcen A, Mouna $\mathrm{K}$, et al. Les tumeurs primitives de la glande submandibulaire: à propos de 25 cas. Pan Afr Med J 2014; doi:10.11604/pamj.2015.22.232.7275

[6] Ellies M, Laskawi R, Agrelebe C, Schott A. Surgical management of non-neoplastic diseases of the submandibular gland. A follow-up study. Int J Oral Maxillofac Surg 1996; 25: 285-89.

[7] Adeyemo WL, Ajayi OF, Anunobi CC, Ogunlewe MO, Ladeinde AL, Omitola OG, et al. Tumours of the submandibular salivary gland: a clinicopathologic review of cases over a 17-year period. West Indian Med J 2009 Sep; 58 (4): 388-91.

[8] Rapidis AD, Stavrianos S, Lagogiannis G, Faratzis G. Tumors of the submandibular gland: Clinicopathologic analysis of 23 patients. J Oral Maxillofac Surg 2004; 62: 1203-8.

[9] Hamoir M, Lawson G, Andry G, Lothaire P, Sacre R, Remacle $\mathrm{M}$, et al. Tumors of the submaxillary gland. Ann Otolaryngol Chir Cervicofac 1991; 108 (1): 26-9.

[10] Just PA, Miranda L, Elouaret Y, Meatchi T, Hans S, Badoual C. Classification des tumeurs des glandes salivaires. Ann Otolaryngol Chir Cervicofac 2008; 125 (6): 331-40.

[11] Pegbessou EP, Ndiaye M, Diom E, Thiam A, Diouf MS, Boube D, et al. Tumeurs sub-mandibulaires: profils épidémiologiques et histologiques. Pan Afr Med J 2014; doi: 10.11604/pamj.2014.18.64.2102

[12] Halimi P, Gardner M, Petit F. Les tumeurs des glandes salivaires. Cancer Radiother 2005; 9: 251-60.

[13] Baglin AC, Wassef M. Cytoponction des glandes salivaires: le pour et le contre. Ann Pathol 2007; 27: 1S69-1S80.

[14] Kucuk U, Akoz G, Cakir E, Pala EE, Bayol U, Gumussoy M, et al. Documentation of the Salivary Gland Tumors: An institutional data from Turkey. Med Sci Discov 2015; 2 (1): 144-47.

[15] Vargas PA, Gerhard R, Araujo Filho VJ, de Castro IV. Salivary gland tumors in a Brazilian population: a retrospective study of 124 cases. Rev Hosp Clin Fac Med Sao Paulo 2002; 57 (6): 271-6.

[16] Vuhahula EAM. Salivary gland tumors in Uganda: clinical pathological study. Afr Health Sci 2004; 4 (1): 15-23.

[17] Amana B, Pegbessou E, Boko E, Agoda P, Darre T, Kpemissi $\mathrm{E}$, et al. Tumeurs malignes de la parotide: épidémiologie au Togo. Rev Stomatol Chir Maxillofac Chir Orale 2014; 115: $15-6$. 